\title{
Explorations of subjective wellbeing and character strengths among a Greek University student sample
}

\author{
Sophie Leontopoulou · Sofia Triliva
}

\begin{abstract}
The present study brought together and examined two related, but distinct, concepts rooted in positive psychology, namely subjective wellbeing (SWB) and character strengths. It sought to assess the impact of a number of demographic and other sociological and psychological factors, including physical and mental health, on emerging adults' outlook on life. This study also set out to validate and investigate the levels of wellbeing and character strengths in the context of a more collective, Mediterranean culture; that of Greece. Three hundred and twelve male and female students from two Greek Universities participated in the study, which consisted of a questionnaire battery, including measures of subjective wellbeing, character strengths and mental and physical health. Youths were found to have a positive outlook on life. Wisdom, courage and transcendence appeared to be the most salient among their character strengths, since character strengths were each highly and positively correlated with the wellbeing subscales of environmental mastery, purpose in life and self-acceptance. Good physical and mental health were positively related to, and reliably predicted different aspects of, both wellbeing and character strengths; nevertheless, mental health appeared to affect and predict more aspects of wellbeing and character strengths than physical health. The significance of the above findings for the field of positive psychology is discussed.
\end{abstract}

Keywords: subjective wellbeing, character strengths, mental and physical health, emerging adulthood, positive psychology

\section{Introduction}

Over the last decade there has been a dramatic rise in research that comes under the broad umbrella of the "positive psychology field" (Noble \& McGrath, 2008; Peterson, Park, \& Sweeney, 2008). In their editorial to the millennium issue of the American Psychologist, Seligman and Csikszentmihalyi proposed that a science of "positive subjective experience, positive individual traits and positive institutions" had much to offer in terms of improving the quality of life and in helping prevent certain types of mental illness (Seligman \& Csikszentmihalyi, 2000). Since then the field has expanded considerably and 'positive psychology' research has made a number of valuable contributions to a diverse range of individual disciplines encompassed by mainstream psychology, such as Organizational, School and Counselling Psychology (Luthans, Avey, Avolio, Norman, \& Combs, 2006; Lopez \& Edwards, 2008; Miller, Nickerson, Chafouleas, \& Osborne, 2008). 


\subsection{The role of subjective wellbeing in mental health}

One area of positive psychology that has attracted particular attention within the clinical domain has been the role that an individual's sense of subjective wellbeing (SWB) plays in their mental health. Subjective wellbeing refers to the different ways in which people evaluate the quality of their lives (Diener, 2000; Diener, Kesebir \& Lucas, 2008), and is seen as being made up of an interaction of cognitive and affective components. For example, those people who judge their lives to be rewarding and fulfilling and in general experience positive rather than negative moods are those deemed to be experiencing high levels of subjective wellbeing. There are a variety of external and internal factors that are seen as contributing towards an individual's sense of subjective wellbeing-for example, physical health, financial status, job satisfaction and career opportunities, being involved in meaningful and rewarding social relationships, and the experience of certain major life events and underlying personality traits, such as extraversion (for a review see: Weiss, Bates, \& Luciano, 2008).

There is now a substantial body of research that indicates that across the globe people have a tendency to rate themselves as being more satisfied than dissatisfied with life, averaging 7/10 in measures of SWB (Diener, 2000). As Myers (2000) points out, this raises the question whether seemingly satisfied and happy people are merely in denial of their actual misery. Or to put it another way, given that measures of SWB are by their very nature self-report indexes, does the self-report nature of SWB indexes represent individuals' tendencies towards unrealistic positive bias as a protective mechanism? However, it would appear to be the case that SWB does demonstrate convergent validity, as people who report that they are happy appear to be so to family and friends also. In addition, people who report being happy seem to be less hostile and abusive to others and also less vulnerable to disease, compared to people who are depressed (Myers, 2000). Certain personality traits that have been linked to SWB and to 'character strengths' may account for the above findings.

\subsection{Personality traits associated with subjective wellbeing and character strengths}

Recently, there has been increased interest shown in exploring the relationship between 'character strengths' and SWB. Much of this work has been carried out by Martin Seligman and his colleagues in the United States at the VIA Institute (www.viacharacter.org/. Also see e.g. Park, Peterson \& Seligman, 2004; Peterson, Ruch, Beermann, Park, \& Seligman, 2007). Character strengths have been defined as "positive traits reflected in thoughts, feelings and behaviours" (Park, et al., 2004, p. 613). Under their taxonomy there are 24 strengths, and examples of character strengths include hope, gratitude, modesty, appreciation of beauty, curiosity, judgement and love of learning. These 24 strengths are classified into six broader categories, namely autonomy, environmental mastery, personal growth, positive relations, purpose in life, and self-acceptance (Figure 1 portrays the classification of the character strengths). According to Eysenck (1991), character traits are universally recognised and grounded in biology - as part of an evolutionary process that selects for 'moral excellence' as a means of solving important tasks necessary for the survival of the species.

The relationship between character strengths and SWB would appear to be complex since some-but certainly not all-character strengths appear to have a direct relationship with subjective wellbeing (Brdar \& Kashdan, 2010). From the research evidence available to date, it would appear that whereas the qualities of hope, zest, gratitude, love, and curiosity correlate highly with measures of life satisfaction, certain other diverse character strengths - which include the qualities of modesty, appreciation of beauty and love of learning - do not (Park, et al., 2004). As a result of several years of research, Seligman and colleagues have constructed a 


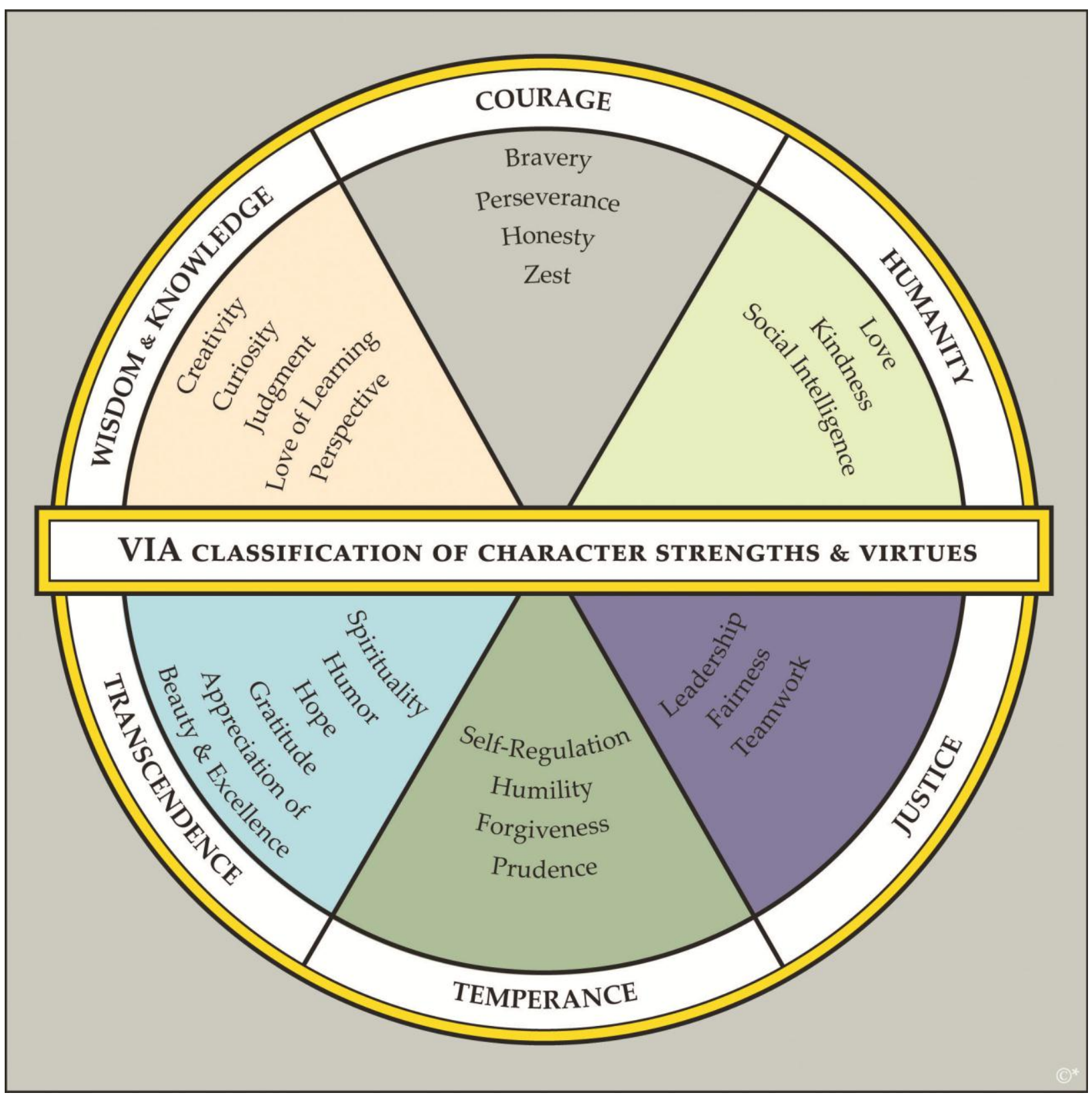

Note: VIA Classification is copyrighted material of VIA Institute on Character, 2004. See www.viacharacter.org. Used with permission. This image first appeared in Niemiec (2012, p. 24). Duplication of this image requires permission from the VIA Institute, and a reference to Niemiec (2012).

\section{Figure 1: VIA Classification}

widely used scale to measure character strengths-'Seligman's VIA Survey of Character Strengths' (Seligman, 2002), a 48-item version of the main 240-item scale titled 'VIA Inventory of Strengths (VIA-IS)' (Peterson, Park, \& Seligman, 2005). To date, much of the data regarding the reliability and construct validity of the scale have been derived from US samples (Stone, Schwartz, Broderick, \& Deaton, 2010); however, some interesting cross-national findings have also emerged. For example, in a comparative study of US and Swiss nationals it was found that the character strengths most predictive of life satisfaction in both groups were love, hope, curiosity and zest. However, it was also found that whilst 'gratitude' was among the strongest predictors of life satisfaction within the US sample, 'perseverance' was a more robust predictor of life satisfaction amongst the Swiss group (Peterson, et al., 2007). In a study of character strengths within the 50 US states Park, Peterson and Seligman (2006) reported that the most 
common ones (in order) were 'kindness', 'fairness', 'honesty', 'gratitude', and 'judgment', while the least common were 'prudence', 'modesty', and 'self-regulation'. The only strength that differed within the different states was 'religiousness'.

\subsection{Subjective wellbeing of university students}

The transition that young people make between school and university is for many an exciting, yet challenging, time. On the one hand, the university experience provides the young person with the opportunity to enhance knowledge and perspective, to develop and establish aspects of personal identity and to achieve personal growth (Giovazolias, Karademas, \& KalantziAzizi, 2008). On the other hand, during the time that young people are at university, many of them will encounter a number of novel, practical, academic as well as social, emotional and psychological difficulties (Leontopoulou, 2006). Developing new social and romantic relationships, problems with living accommodation, difficulties with coping with new-found independence, separation anxiety that may be experienced by being away from one's family, financial worries, health care concerns and coping with the demands of academic work are just some of the typical problems that many students will face (Halamandaris \& Power, 1997). Furthermore, these individual challenges may not occur independently of one another. For example, problems with social and/or romantic relationships may heighten the separation anxiety experienced by being away from home and support networks, and this in turn may reduce engagement in study. As another example, problems with living accommodation may increase financial worries (and vice versa), and poor physical health may restrict levels of social interaction, which in turn may lead to increased loneliness and feelings of isolation.

\subsection{Cultural considerations: Concepts and measurement tools}

Becker and Marecek (2008) argue that the ethos of 'positive psychology' and its associated measurement tools are culturally bound. They claim that although the field promotes itself globally, its American roots are apparent, particularly in the way that the field endorses the individualistic goals of self-fulfilment and self-improvement, and in its "narrow view of the social" (Becker \& Marecek, 2008, p. 1767). In contrast, Mediterranean societies such as Greece have traditionally been portrayed in the social science literature as being community- and family-oriented cultures (Markus \& Kitayama, 1991; Triandis, 1995). It is possible that the theoretical underpinnings of positive psychology may have less validity as a research paradigm when applied to Greek students than to their counterparts in the United States and Northern Europe. To date there has been little research carried out that has sought to investigate the relative construct and convergent validity of US-derived positive psychology measurement tools among Greek samples. It is clear, then, that further work in this area is needed.

\subsection{The present study}

The overall focus of the present study was to investigate emerging adults' outlook on life. More specifically, the study had three main aims. The first was to examine simultaneously two related, but distinct, concepts rooted in positive psychology, namely SWB and character strengths, in emerging adulthood. Research evidence linking the two concepts for Greek emerging adults is scarce and widely spread in time, let alone studies mapping the relations between their respective subscales. Therefore, conceptual affinities between the two concepts were sought in an effort to identify specific ways in which each construct impacts on the other during emerging adulthood. 
The second aim of this study was to investigate the impact of a number of demographic and other sociological and psychological factors on emerging adults' outlook on life, since such factors have been known to affect SWB (Diener, Tamir, \& Scollon, 2006). The present study investigated University students' (1) demographic characteristics (such as age, gender and socio-economic status); (2) academic information; (3) relationship information (romantic, social, with parents); (4) information about accommodation and working; and (5) physical and mental health. Of particular interest were the possible patterns of relations between physical and mental health, subjective wellbeing and character strengths.

To date the vast majority of studies linking SWB and character strengths has been carried out in North American and North European societies. Relatively little research has been carried out in the above direction in societies beyond that range. In one of the few studies that have been carried out outside North America and North Europe, Toner, Haslam, Robinson and Williams (2012) found that in an Australian adolescent sample the character strengths of temperance, vitality, and transcendence were associated with subjective wellbeing and happiness. Brdar and Kashdan (2010) investigated the relationship between character strengths and SWB in Croatian University students and found that strengths associated with vitality (such as zest, curiosity, gratitude, and optimism/hope) were strongly associated with increased SWB. Given that North American and North European societies, such as the United States, United Kingdom and Sweden are largely considered to be more individualistic in nature than other societies, such as Greece, which is a more collectivist one (Triandis, 1995), differences may be expected in the nature and direction of any results linking SWB and character strengths. Therefore, the third aim of this study was to provide reliable measurements of both wellbeing and character strengths and their subscales, validated for use with a Greek sample. To the best of our knowledge, this is the first time this has been attempted.

\section{Method}

\subsection{Sample}

Information regarding participants' demographic and other social and psychological characteristics is presented in Tables 1 and 2. Figure 2 portrays students' self-reported physical and mental health status.

With regard to satisfaction with living conditions, first-year students were happier with their living arrangements than the rest $(F(1,309)=4.94, p<.05)$, possibly because this was their first time living on their own, away from home and perhaps because entering University is a major accomplishment, a personal achievement which allows students to feel good about themselves and their lives.

Two groups of students, those who were satisfied with their living conditions, and those who were not, were further examined in order to identify any other potential sources of support they might be enjoying. Significant differences were observed between the two groups. In particular, the more satisfied the participants were with their living conditions, the more likely they were $(1)$ to be romantically involved $\left(\chi^{2}(4,311)=9.93, p<.05\right)$; and also $(2)$ to see and talk to a greater number of close friends on campus $\left(\chi^{2}(28,26)=43.62, p<.05\right)$. Interestingly, (3) those satisfied with their living conditions tended to report better mental health as well $\left(\chi^{2}(8,299)=23.9, p<.01\right)$. These findings are in line with previous research suggesting that satisfactory living conditions, as indicators of quality of life, lead to higher satisfaction with life at both a personal and a national level (Saris, 2001; Veenhoven, 1996). 


\subsection{Measures}

The questionnaire battery used in this study included a total of 155 questions. Twenty-three of these questions were developed to obtain information about our sample on a number of variables. These variables included (1) demographic information (i.e. age, gender, marital and socio-economic status, country of origin); (2) academic information (i.e. year of study, reregistration from another University, number of exams passed last semester, amount of time spent studying, academic performance); (3) relationship information (i.e. involvement in a romantic relationship, sexual preference, social relationships, involvement in academic and social activities, frequency of communication with parents); (4) information about accommodation and working (i.e. accommodation and satisfaction with it, working and time spent at work); and (5) physical and mental health (self-assessment of one's physical and mental health on a four-point Likert-type scale (i.e. "excellent", "good", "average" and "poor"; the option "very poor" as a fifth point in the scale was not included, as concerns were raised that students would not select it in order to present themselves in a favourable light. A high score in the scale indicated better health).

Students' SWB was assessed with the use of 'The Psychological Well-Being Scales' (PWBS Short Scales; Ryff, 1989). This version of the PWBS included 84 items and answers were on a six-point agree-disagree Likert-type scale. The response range was from "strongly disagree" to "strongly agree". A high score on the PWBS is deemed to indicate a high sense of subjective wellbeing. Cronbach's alpha for the whole scale was high, $a=.92$. The PWBS comprises six subscales, namely autonomy, environmental mastery, personal growth, positive relations, purpose in life, and self-acceptance, which have previously been reported to have good internal consistency, Cronbach's alpha ranging from $a=.87$ to $a=.93$, good test-retest reliability, $r=.81$ to $r=.88$, and good validity. Cronbach's $a$ in the Greek sample for each subscale was $a=.80$ for autonomy, $a=.77$ for environmental mastery, $a=.80$ for personal growth, $a=.81$ for positive relations, $a=.75$ for purpose in life and $a=.74$ for self-acceptance. Sample items included "In general, I feel I am in charge of my life" (personal growth subscale) and "Keeping close friends has been difficult for me" (positive relations subscale).

Seligman's 48-item 'VIA Survey of Character Strengths' (SCS; Seligman, 2002) was used to index students' character strengths. The response range on this five-point Likert-type scale was "very much like me", "like me", "neutral", "unlike me", "very much unlike me”. Each strength is measured by two items, a positively and a negatively phrased one. A high score on the SCS suggested that participants manifested high scores on a number of character strengths. The reliability of the whole scale in the Greek sample was high (Chronbach's $a=.82$ ). The VIA SCS scale includes six subscales, namely wisdom $(a=.76)$, courage $(a=.76)$, justice $(a=.70)$, human love $(a=.74)$, temperance $(a=.69)$ and transcendence $(a=.75)$. Sample items included "I am always curious about the world" (wisdom subscale) and "I am in control of my feelings" (temperance subscale). There is some debate in the literature regarding the structure of the VIA SCS. For example, Toner, et al. (2012) reported the existence of three- and four-factor solutions in the literature, while in their study they identified five factors. Since this was the first time that the VIA SCS scale was administered to a Greek sample we chose to use the original six factors and investigate their potential relationship to the SWB subscales.

\subsection{Procedure}

The questionnaire battery of 155 questions described above was administered to students during the lectures of the participating course instructors at each of the University departments. A researcher was always present and available for clarifications for the duration 
of the questionnaire completion, which usually took about 45 minutes. Students signed informed consent forms for their participation in the research endeavour and they were reassured regarding confidentiality. No financial rewards or course incentives were offered to participants.

Table 1: Demographic, sociological and psychological characteristics of the sample $(N=312)$

\begin{tabular}{|c|c|}
\hline Characteristic & Value \\
\hline Age & $\mathrm{M}=19.9(\mathrm{SD} 2.59)$ \\
\hline \multicolumn{2}{|l|}{ Gender } \\
\hline Male & $73(23.5 \%)$ \\
\hline Female & $238(76.5 \%)$ \\
\hline \multicolumn{2}{|l|}{ Origin } \\
\hline Greek & $281(90.3 \%)$ \\
\hline European & $27(8.7 \%)$ \\
\hline Other & $3(1 \%)$ \\
\hline \multicolumn{2}{|l|}{ Living situation } \\
\hline Alone & $175(56 \%)$ \\
\hline Parents & $45(14 \%)$ \\
\hline Friends & $74(24.4 \%)$ \\
\hline Other & $18(5.6 \%)$ \\
\hline \multicolumn{2}{|l|}{ Satisfaction with living situation } \\
\hline Very/a little satisfied & $249(79.8 \%)$ \\
\hline Neither satisfied nor dissatisfied & $44(14 \%)$ \\
\hline Very/a little dissatisfied & $19(6.1 \%)$ \\
\hline \multicolumn{2}{|l|}{ Romantic relations } \\
\hline Single & $163(52.4 \%)$ \\
\hline Attached & $148(47.4 \%)$ \\
\hline \multicolumn{2}{|l|}{ Contact parents at least $1 / 15$ days } \\
\hline Mother & $43(15.4 \%)$ \\
\hline Father & $3(1.1 \%)$ \\
\hline Both & $230(82.1 \%)$ \\
\hline Neither & $4(1.4 \%)$ \\
\hline \multicolumn{2}{|l|}{ Frequency going out past 15 days } \\
\hline$>10$ times & $62(20.7 \%)$ \\
\hline $5-9$ & $110(36.8 \%)$ \\
\hline $2-4$ & $102(34.1 \%)$ \\
\hline 1 & $19(6.4 \%)$ \\
\hline 0 & $6(2 \%)$ \\
\hline
\end{tabular}


Table 2: Academic and employment characteristics of the sample $(\mathrm{N}=312)$

\begin{tabular}{|c|c|}
\hline Characteristic & Value \\
\hline \multicolumn{2}{|l|}{ University } \\
\hline Peireaus & $79(25.9)$ \\
\hline Crete & $226(74.1)$ \\
\hline \multicolumn{2}{|l|}{ Year of study } \\
\hline $1^{s t}$ & $77(24.8 \%)$ \\
\hline $2^{n d}$ & $90(28.9 \%)$ \\
\hline $3^{r d}$ & $3(1 \%)$ \\
\hline $4^{\text {th }}$ & $34(10.9 \%)$ \\
\hline$>4^{\text {th }}$ & $108(34.3 \%)$ \\
\hline N Exams passed & $\mathrm{M}=5.5(\mathrm{SD} 1.83)$ \\
\hline \multicolumn{2}{|l|}{ Acad. Performance } \\
\hline$>5$ (Fail) & $6(2.6 \%)$ \\
\hline $5-6$ & $17(7.5 \%)$ \\
\hline $6-7$ & $76(33.3 \%)$ \\
\hline $7-8.5$ & $112(49.1 \%)$ \\
\hline $8.5-10$ & $17(7.5 \%)$ \\
\hline Hrs of study per week & $\mathrm{M}=7.2(\mathrm{SD} 7.35)$ \\
\hline \multicolumn{2}{|l|}{ Work } \\
\hline Yes & $29(9.3 \%)$ \\
\hline No & $283(90.7 \%)$ \\
\hline Work hrs per week & $\mathrm{M}=17.3(\mathrm{SD} 12.16)$ \\
\hline Volunteer work hrs per week & $\mathrm{M}=2.5(\mathrm{SD} .7)$ \\
\hline
\end{tabular}
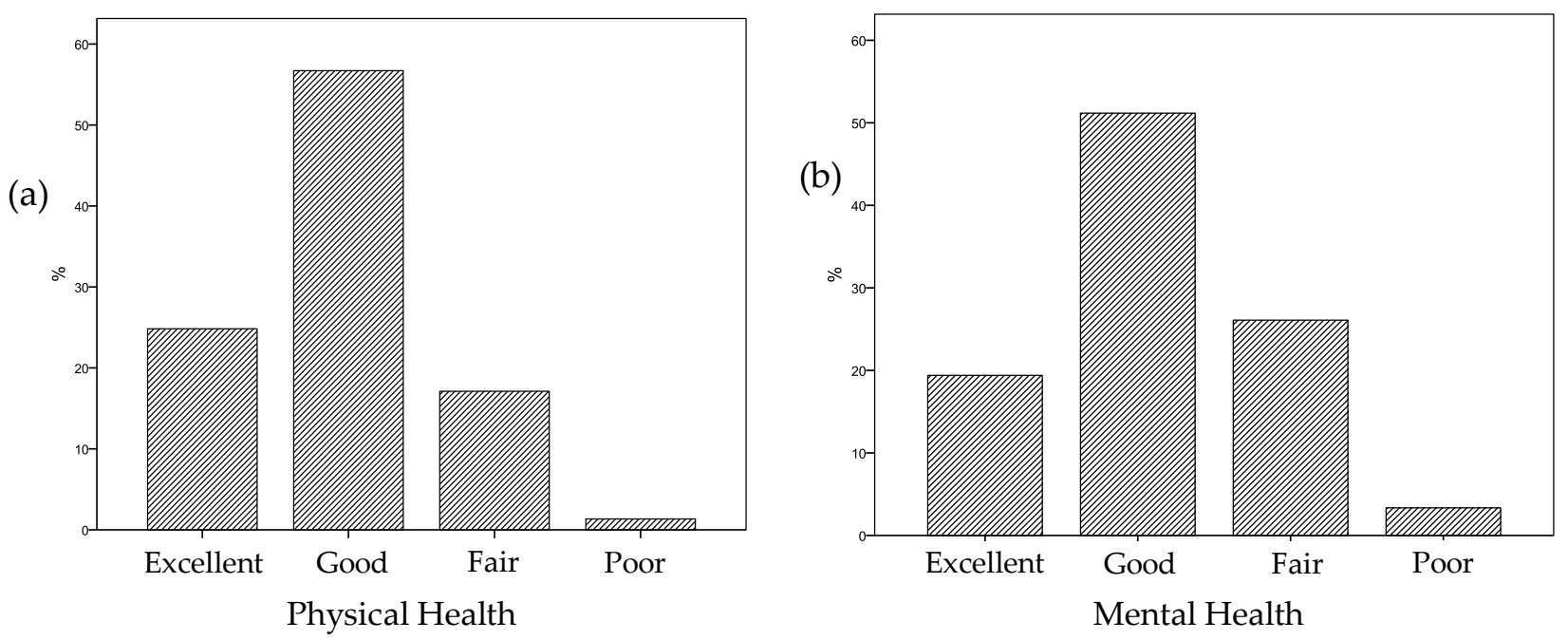

Figure 2: Self-reported status of participants' (a) physical and (b) mental health 


\section{Results}

On Ryff's Psychological Well-Being Scales (PWBS) our sample had a mean of $M=4.23$, with a standard deviation of $S D=.50$. Even though a positive skew was evident in the data, tests for normality of data distribution did not reveal any significant deviations from the norm. Seligman's VIA Survey of Character Strengths (SCS) scale had a mean of $M=3.46$ and a standard deviation of $\mathrm{SD}=.35$, thus revealing a positive skew of the data; even so, the data were normally distributed. The positive bias evident in both scales corresponds to previous findings that, in general, people are more likely to rate themselves as being satisfied, rather than dissatisfied, with life (Myers, 2000). Details regarding the mean values and the standard deviations of the SWBS and the VIA SCS, including their respective subscales, can be found in Table 3.

Table 3: Means $(M)$ and Standard Deviations $(S D)$ for the PWBS and the VIA SCS scales and their subscales

\begin{tabular}{llllll}
\hline SWBS & Mean & SD & VIA SCS & Mean & SD \\
\hline Autonomy & 3.96 & .67 & Wisdom & 3.52 & .46 \\
Environ. mastery & 3.91 & .64 & Courage & 3.44 & .57 \\
Personal growth & 4.40 & .55 & Human love & 3.87 & .44 \\
Positive relations & 4.43 & .76 & Justice & 3.42 & .58 \\
Purpose in life & 4.46 & .74 & Temperance & 2.91 & .50 \\
Self-acceptance & 4.20 & .82 & Transcendence & 3.55 & .43 \\
Total scale & 4.23 & .50 & Total scale & 3.46 & .35 \\
\hline
\end{tabular}

Subsequently, bivariate correlations were carried out in order to investigate any relations between subjective wellbeing (PWBS) and character strengths (SCS). The literature so far indicates that some character strengths correlate to wellbeing, while others do not (Brdar \& Kashdan, 2010). From the data available to date (Park, et al., 2004; Peterson, et al., 2007), one could expect that the wisdom, human love and transcendence subscales of the SCS would correlate well with the overall PWBS scale and its subscales, as the qualities of hope, zest, gratitude, love, and curiosity, which form the above subscales, have been found to correlate well with indices of life satisfaction cross-culturally; on the other hand, low, if any, correlations could be expected between the temperance subscale of the SCS and wellbeing, since modesty was not found to relate to life satisfaction (Peterson, et al., 2007). Table 4 shows the correlations found between the overall scales of wellbeing and character strengths and their subscales.

Significant, high and positive correlations were found between subjective wellbeing and character strengths $(r=.70, p<.001)$, indicating high convergent validity for the two measures. The contributions from all the wellbeing subscales to the overall character strengths scale were significant, the highest being from the purpose of life $(r=.62, p<.001)$, the environmental mastery $(r=.61, p<.001)$ and the self-acceptance $(r=.61, p<.001)$ subscales. All contributions of the character strengths subscales to the overall wellbeing scale were also significant, the highest of which were from the courage $(r=.62, p<.001)$, transcendence $(r=.59, p<.001)$ and wisdom $(r$ $=.58, p<.001)$ subscales. Temperance seemed to stand out from the other subscales, since it had a somewhat lower mean, as reported above, and also did not correlate well with either the overall wellbeing scale or its subscales. Almost all correlations between the six subscales of Ryff's PWBS and the six subscales of Seligman's SCS measures were significant. Figure 3 portrays some of the highest correlations found between the VIA SCS and the PWBS subscales. 
Table 4: Correlations between subjective wellbeing and character strengths

\begin{tabular}{|c|c|c|c|c|c|c|c|}
\hline & 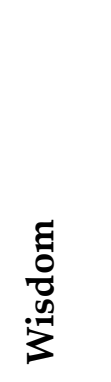 & 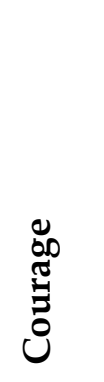 & 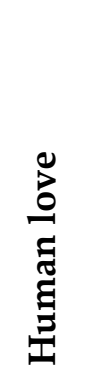 & 莺 & 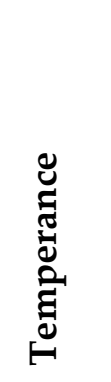 & 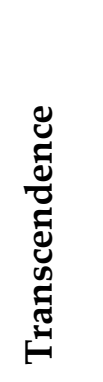 & 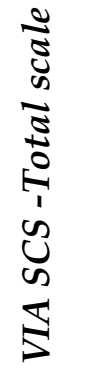 \\
\hline Autonomy & $.35^{* *}$ & $.47^{* *}$ & .09 & $.25^{* *}$ & .01 & $.31^{* *}$ & $.39 * *$ \\
\hline Environmental mastery & $.46^{* *}$ & $.58^{* *}$ & $.19^{*}$ & $.37^{* *}$ & $.23^{* *}$ & $.54^{* *}$ & $.61^{* *}$ \\
\hline Personal growth & $.45^{* *}$ & $.23^{* *}$ & $.28^{* *}$ & $.24^{* *}$ & -.05 & $.38^{* *}$ & $.43^{* *}$ \\
\hline Positive relations & $.26^{* *}$ & $.27^{* *}$ & $.39 * *$ & $.27^{* *}$ & .02 & $.29^{* *}$ & $.37^{* *}$ \\
\hline Purpose in life & $.50^{* *}$ & $.55^{* *}$ & $.29^{* *}$ & $.37^{* *}$ & $.18^{*}$ & $.50^{* *}$ & $.62^{* *}$ \\
\hline Self-acceptance & $.50^{* *}$ & $.56^{* *}$ & $.24^{* *}$ & $.27^{* *}$ & $.27^{* *}$ & $.52^{* *}$ & $.61^{* *}$ \\
\hline PWBS - Total scale & $.58^{* *}$ & $.62^{* *}$ & $.35^{* *}$ & $.41^{* *}$ & $.17^{*}$ & $.59^{* *}$ & $.70^{* *}$ \\
\hline
\end{tabular}

${ }^{*} p<.01{ }^{* *} p<.001$

(a)

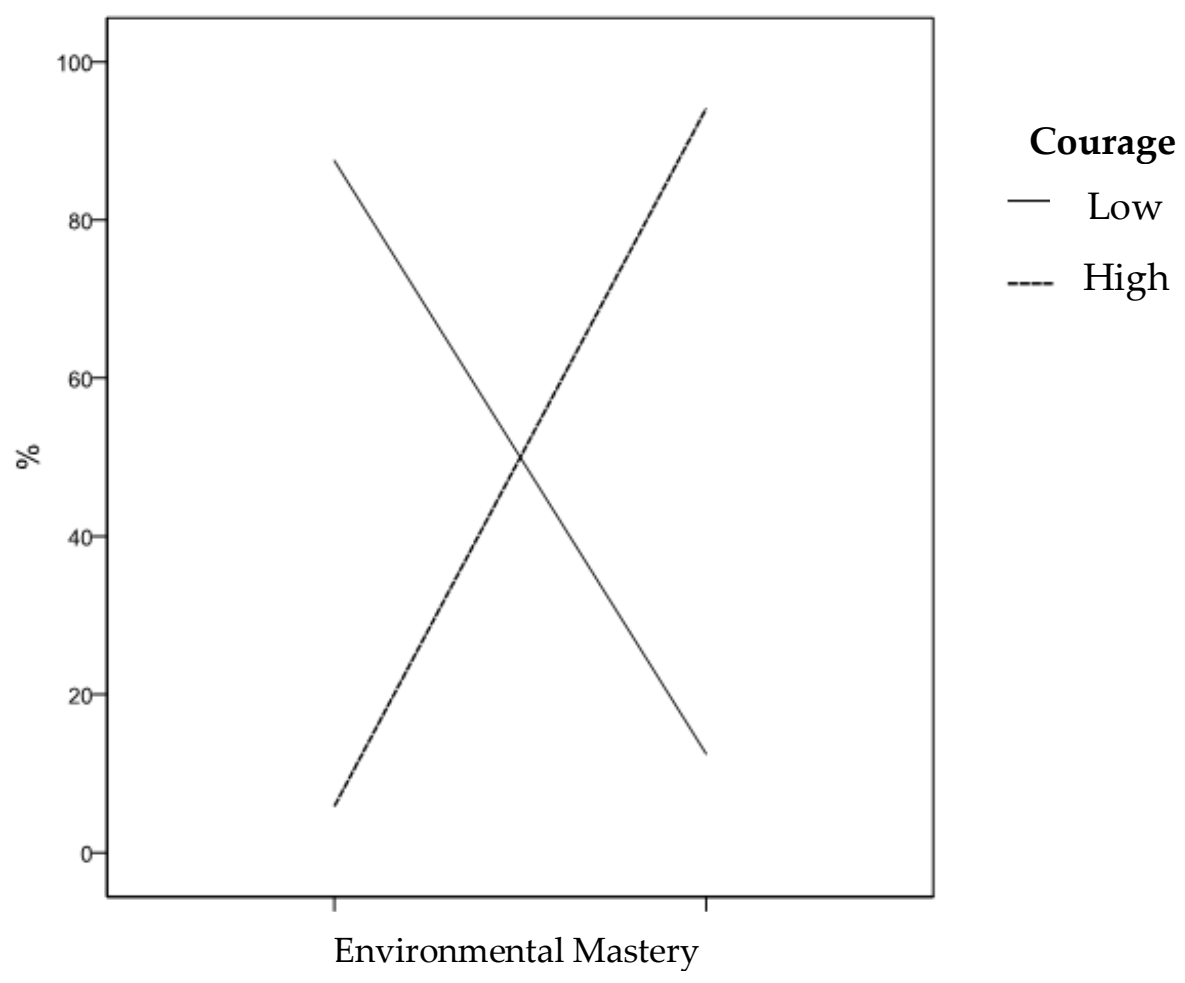

Figure 3(a): Relations between the VIA SCS and the PWBS subscales: Environmental Mastery and Courage 
(b)

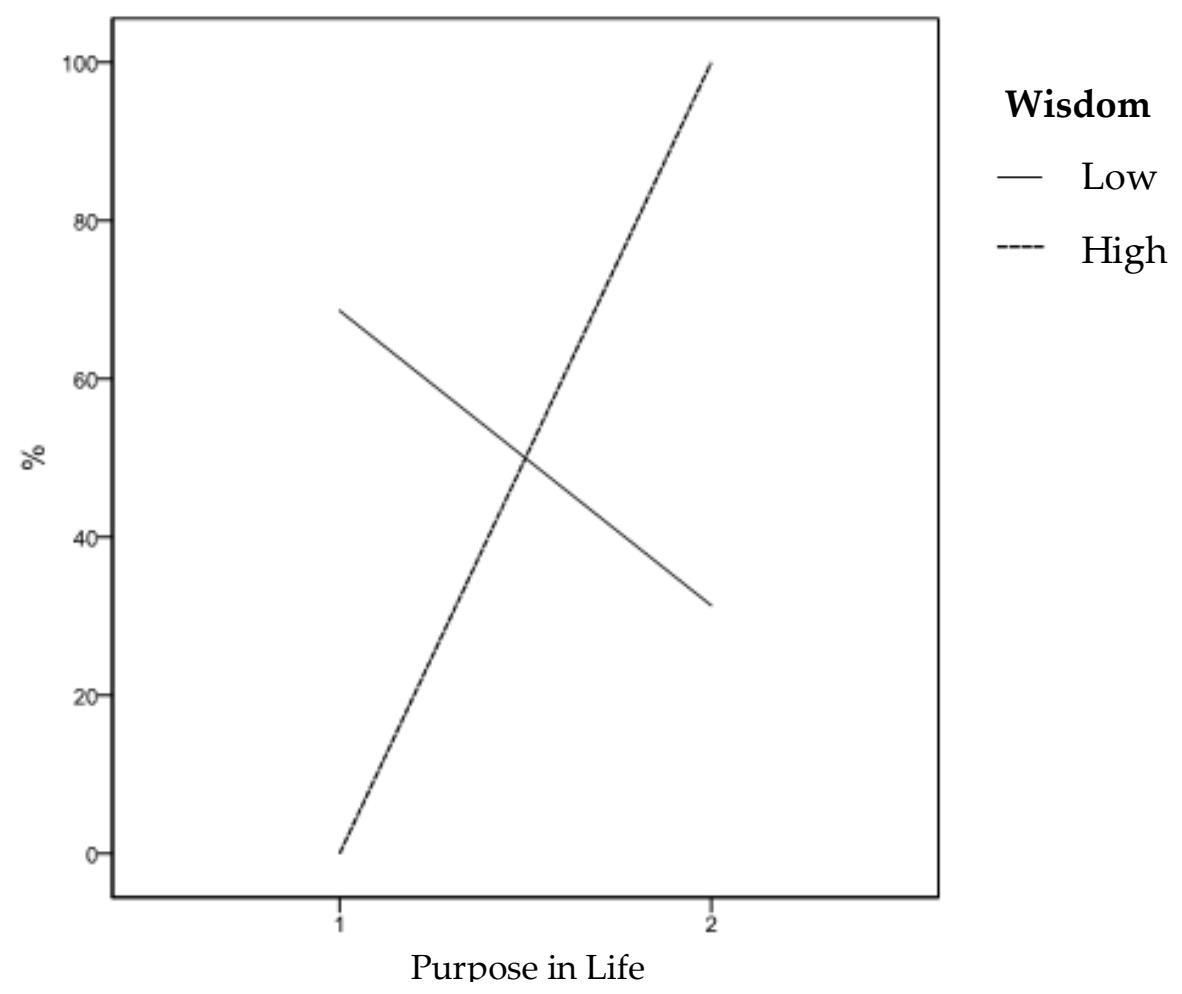

Figure 3(b): Relations between the VIA SCS and the PWBS subscales: Purpose in life and Wisdom

(c)

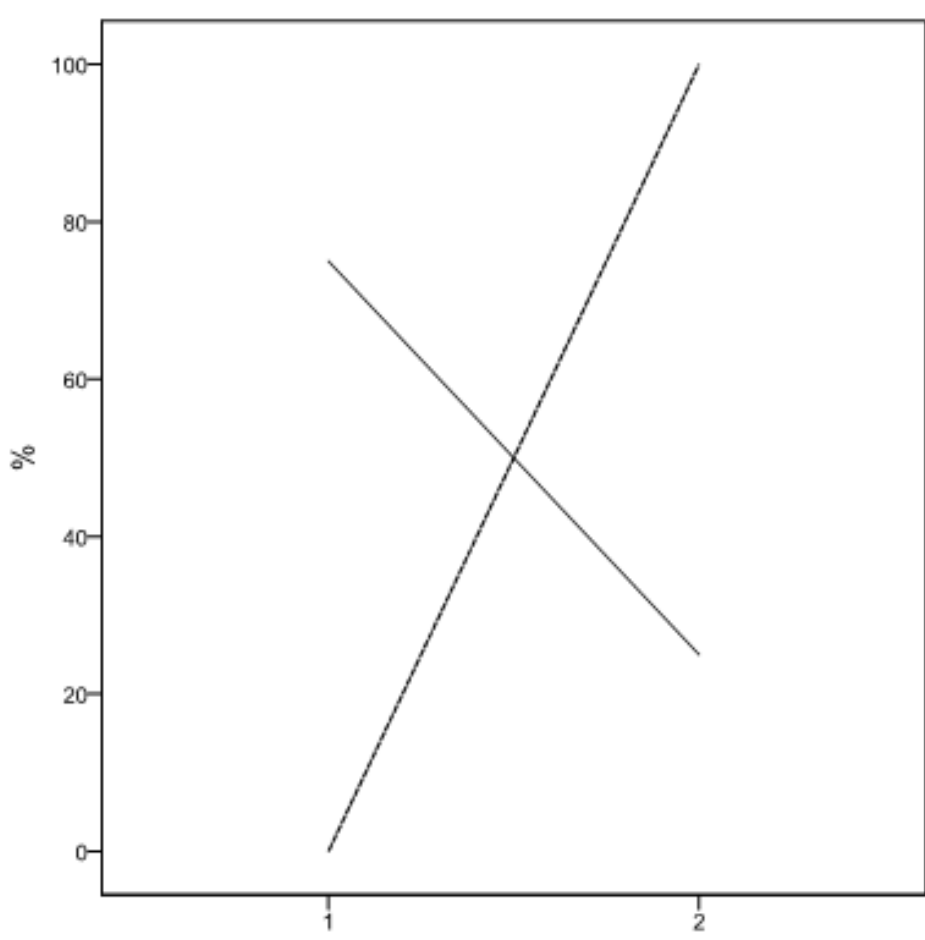

Transcendence

- Low

---- High

Self-acceptance

Figure 3(c): Relations between the VIA SCS and the PWBS subscales: Self-acceptance and Transcendence 
3.1 Relationship between demographic and other sociological and psychological factors, subjective wellbeing and character strengths

The only significant difference that was found on the overall wellbeing scale with the aid of a one-way ANOVA revealed that country of origin differentiated participants, in such a way that Greeks raised in Greece reported higher levels of wellbeing than students from non-European countries $(F(187,56)=1.67, p<.01)$. Subsequently, a set of t-tests and one-way ANOVAs helped the identification of significant differences among participants with respect to the six wellbeing subscales (see Table 5 for summary of significant findings). It is worth mentioning that mental health problems were more pervasive than physical ones, in that they significantly affected all subscales of wellbeing, except that of personal growth, in the expected direction. Overall, the findings regarding mental health suggested that self-reports of mental health status related well to the subjective wellbeing scale as a whole.

In terms of character strengths, significant differences were identified for the whole scale, as follows: (1) for participants' marital status $(F(92,218)=3.88, p<.001)$; (2) for being pleased with one's living conditions $(F(93,218)=1.65, p<.001)$; and $(3)$ for self-reported physical health $(F$ $(91,206)=1.41, p<.05)$. T-tests and one-way ANOVAs were also carried out for each of the six subscales of the SCS (see Table 6 for summary of significant findings). On the whole, the relationship between mental health and character strengths appeared to be as consistent as that for subjective wellbeing.

\subsection{Mapping the relations between subjective wellbeing, character strengths, physical and mental health and other demographic and sociological and psychological factors}

Two hierarchical regression analyses helped clarify the relations between subjective wellbeing, character strengths, physical and mental health and other demographic and sociological and psychological factors in our sample. The first regression was performed to identify those factors that might predict overall levels of students' wellbeing. Age, gender and academic performance were entered into the regression equation first, followed by self-ratings of physical and mental health on the second and third step respectively and by all of the character strengths subscales at the last step. All independent variables, but for the demographic ones, proved to be strong predictors of subjective wellbeing (see Table 7 for details). In particular, those with selfreported physical and mental health problems reported lower levels of subjective wellbeing, as did those who scored higher in the character strengths scales of wisdom, courage, human love and transcendence.

The second regression was performed to identify those factors that might predict overall levels of students' character strengths. Age, gender and academic performance were entered into the regression equation first, followed by self-ratings of physical and mental health on the second and third step respectively and by all of the subjective wellbeing subscales at the fourth step. All independent variables proved to be strong predictors of character strengths (see Table 8 for details). In particular, older students and students with higher academic performance appeared to enjoy higher levels of wellbeing, as did those with less self-reported physical and mental health problems and also those who scored higher in the wellbeing scales of personal growth and self-acceptance. 
Table 5: Significant demographic, sociological and psychological, physical and mental health differences in the six subjective wellbeing subscales (PWBS)

\begin{tabular}{llll}
\hline Characteristic & $\mathbf{d f}$ & $\mathbf{t}$ & Difference \\
\hline $\begin{array}{l}\text { Gender } \\
\quad \begin{array}{l}\text { Personal growth } \\
\text { Positive Relations }\end{array}\end{array}$ & 242 & $2.19^{*}$ & $\begin{array}{l}\text { Females }>\text { Males } \\
\text { Females }>\text { Males }\end{array}$ \\
$\begin{array}{l}\text { Year of Study } \\
\text { Autonomy }\end{array}$ & 242 & $2.31^{*}$ & \\
$\quad$ & & \\
$\quad$ Environ. mastery & 242 & $2.15^{*}$ & Freshmen $<$ Others \\
$\quad 242$ & $1.96^{*}$ & Freshmen $<$ Others \\
& 242 & $2.61^{* *}$ & Freshmen $<$ Others
\end{tabular}

\section{Romantic relations}

Environ. mastery

In Relation> No Relation

Purpose in life

Self-acceptance

\section{Work}

Autonomy

\section{Pleased with living situation}

$\begin{array}{llll}\text { Environ. mastery } & 4,240 & 4.38^{* *} & \text { Pleased }>\text { Not pleased } \\ \text { Positive relations } & 4,240 & 4.47^{* *} & \text { Pleased }>\text { Not pleased } \\ \text { Self-acceptance } & 4,240 & 4.43^{* *} & \text { Pleased }>\text { Not pleased }\end{array}$

\section{Greeks raised in GR vs. others}

Environ. mastery

3, $240 \quad 3.98^{* *} \quad$ Greeks raised in GR $>$ others

Frequency going out with others
Positive relations
4,227
$2.59^{*}$
Frequent $>$ Infrequent

\section{Talking to friends}

Positive relations

$7,221 \quad 3.98^{* * *} \quad$ Frequent $>$ Infrequent

\section{Physical health}

$\begin{array}{llll}\text { Environ. mastery } & 3,227 & 3.85^{* *} & \text { Good }>\text { Poor } \\ \text { Self-acceptance } & 3,227 & 2.85^{*} & \text { Good }>\text { Poor }\end{array}$

\section{Mental health}

$\begin{array}{llll}\text { Autonomy } & 3,228 & 6.53^{* * *} & \text { Good }>\text { Fair } \\ \text { Environ. mastery } & 3,228 & 12.46^{* * *} & \text { Good }>\text { Poor } \\ \text { Positive Relations } & 3,228 & 3.46^{* *} & \text { Good }>\text { Fair } \\ \text { Purpose in life } & 3,228 & 3.23^{*} & \text { Good }>\text { Poor } \\ \text { Self-acceptance } & 3,228 & 21.48^{* * *} & \text { Good }>\text { Poor }\end{array}$

${ }^{*} p<.05^{* *} p<.01{ }^{* * *} p<.00$ 
Table 6: Significant demographic, sociological and psychological, physical and mental health differences in the six character strengths subscales (VIA SCS)

\begin{tabular}{|c|c|c|c|}
\hline Characteristic & df & $\mathbf{t}$ & Difference \\
\hline \multicolumn{4}{|l|}{ Gender } \\
\hline Human love & 309 & $2.55^{* *}$ & Females > Males \\
\hline \multicolumn{4}{|l|}{ Year of Study } \\
\hline Justice & 309 & $2.41^{* *}$ & Freshmen $<$ Others \\
\hline Transcendence & 309 & $2.35^{* *}$ & Freshmen $<$ Others \\
\hline \multicolumn{4}{|c|}{ Romantic relations } \\
\hline Wisdom & 309 & $2.05^{*}$ & In Relation $>$ No Relation \\
\hline Courage & 309 & $2.25^{*}$ & In Relation $>$ No Relation \\
\hline \multicolumn{4}{|c|}{ Pleased with living situation } \\
\hline Wisdom & 4,1 & $3.21^{* *}$ & Pleased $>$ Not Pleased \\
\hline Courage & 4,1 & $3.78^{* *}$ & Pleased $>$ Not Pleased \\
\hline Human love & 4,1 & $2.35^{*}$ & Pleased $>$ Not Pleased \\
\hline Justice & 4,1 & $4.06^{* *}$ & Pleased $>$ Not Pleased \\
\hline Transcendence & 4,1 & $4.26^{* *}$ & Pleased $>$ Not Pleased \\
\hline \multicolumn{4}{|c|}{ Contact with parents } \\
\hline Transcendence & 3,275 & $2.7^{*}$ & Frequent $>$ Infrequent \\
\hline \multicolumn{4}{|c|}{ Pass more $\mathrm{N}$ exams } \\
\hline Transcendence & 10,198 & $2.39^{* *}$ & Pass more $>$ Pass less \\
\hline \multicolumn{4}{|l|}{ Physical health } \\
\hline Courage & 3,294 & $3.61^{* *}$ & Good $>$ Poor \\
\hline Justice & 3,294 & $4.12^{* *}$ & Good $>$ Poor \\
\hline \multicolumn{4}{|l|}{ Mental health } \\
\hline Wisdom & 3,295 & $7.86^{* * *}$ & Good $>$ Poor \\
\hline Courage & 3,295 & $9.77^{* * *}$ & Good $>$ Poor \\
\hline Temperance & 3,295 & $3.54^{* * *}$ & Good > Poor \\
\hline Transcendence & 3,295 & $6.78^{* * *}$ & Good > Poor \\
\hline
\end{tabular}


Table 7: Hierarchical regression with subjective wellbeing as the dependent variable and demographic, other sociological and psychological characteristics and character strengths as the independent variables

\begin{tabular}{|c|c|c|c|c|c|c|c|c|c|}
\hline & $d f$ & $F$ & $p$ & Beta & $t$ & $\operatorname{sig} t$ & $R^{2}$ & $\Delta R^{2}$ & $\Delta F$ \\
\hline Age & 3,149 & .65 & .58 & .07 & .90 & .36 & .13 & .13 & .65 \\
\hline Gender & & & & .00 & .03 & .97 & & & \\
\hline Academic performance & & & & .07 & .85 & .39 & & & \\
\hline Physical health & 4,148 & 2.45 & $.04^{*}$ & -.22 & -2.78 & $.00^{* *}$ & .06 & .04 & 7.78 \\
\hline Mental health & 5,147 & 5.94 & $.00^{* * *}$ & -.34 & -4.32 & $.00^{* * *}$ & .16 & .10 & 18.73 \\
\hline Wisdom & 11,141 & 21.18 & $.00^{* * *}$ & .24 & 3.76 & $.00^{* * *}$ & .62 & .45 & 28.34 \\
\hline Courage & & & & .33 & 5.05 & $.00 * * *$ & & & \\
\hline Human love & & & & .18 & 3.09 & $.00^{* *}$ & & & \\
\hline Justice & & & & .07 & 1.26 & .21 & & & \\
\hline Temperance & & & & -.06 & -1.24 & .21 & & & \\
\hline Transcendence & & & & .16 & 2.32 & $.02^{* * *}$ & & & \\
\hline
\end{tabular}

Table 8: Hierarchical regression with character strengths as the dependent variable and demographic, other sociological and psychological characteristics and subjective wellbeing as the independent variables

\begin{tabular}{lccccccccc}
\hline & $d f$ & $F$ & $p$ & Beta & $t$ & sig $t$ & $R^{2}$ & $\Delta R^{2}$ & $\Delta F$ \\
\hline Age & 3,149 & 4.03 & $.00^{* *}$ & .16 & 2.06 & $.04^{*}$ & .07 & .07 & 4.03 \\
Gender & & & & .02 & .28 & .77 & & & \\
Academic performance & & & & .18 & 2.29 & $.02^{*}$ & & & \\
Physical health & 4,148 & 3.56 & $.00^{* *}$ & -.11 & -1.42 & .15 & .08 & .01 & 2.04 \\
Mental health & 5,147 & 4.10 & $.00^{* *}$ & -.19 & -2.41 & $.01^{* *}$ & .12 & .03 & 5.83 \\
Autonomy & 11,141 & 18.81 & $.00^{* * *}$ & .06 & .95 & .34 & .59 & .47 & 27.37 \\
Environmental mastery & & & & .11 & 1.69 & .09 & & & \\
Personal growth & & & & .38 & 4.38 & $.00^{* * *}$ & & & \\
Positive relations & & & & .04 & .55 & .57 & & & \\
Purpose in life & & & & .09 & 1.36 & .17 & & & \\
Self-acceptance & & & & .33 & 3.77 & $.00^{* * *}$ & & & \\
\hline
\end{tabular}

${ }^{*} p<.05^{* *} p<.01{ }^{* * *} p<.001$

\section{Discussion}

\subsection{The concepts of subjective wellbeing and character strengths}

One of the main methodological aims of the present study was to bring together and examine two related but distinct concepts, namely subjective wellbeing and character strengths. Both concepts have their roots in positive psychology, in that they reflect cognitive, behavioral and dispositional characteristics of individuals that are aimed at developing and maintaining a positive outlook in life. Conceptually they also have differences, in that wellbeing portrays a 
way of critically thinking back to one's life achievements and shortcomings and represents one's current evaluation of those; while character strengths delineate one's positive thoughts, feelings and behaviors toward an array of situations (Park, et al., 2004). From the literature it would appear that character strengths may contribute towards wellbeing, but are not necessarily the same thing as wellbeing (Peterson, et al., 2007). In any case, most researchers would agree that character strengths are less well defined in the research literature than is subjective wellbeing. Correlation analyses indicated that wisdom, courage and transcendence seemed to be the most salient among the character strengths, since they were each highly and positively correlated with the wellbeing subscales of environmental mastery, purpose in life and self-acceptance, thus signifying conceptual affinities between these subscales. These same character strengths, along with human love, also proved good predictors of the overall wellbeing measure in our sample. In addition, the wellbeing subscales of personal growth and self-acceptance predicted overall character strengths. The above findings add to the growing literature that seeks to identify eclectic affinities between the character strengths and wellbeing, by way of clarifying which particular character strengths best relate to which aspects of wellbeing (Peterson, et al., 2007).

The constellation of relations between subjective wellbeing, demographic characteristics of students and also self-perceptions of their physical and mental health status were revealing. Higher levels of autonomy were more common amongst those students who were older, those who worked and those who suffered from poor mental health. Environmental mastery was mainly exhibited by older students, students involved in a romantic relationship, those pleased with their living situation, those who were Greeks raised in Greece, and those who enjoyed good physical and mental health. Personal growth was more evident in females and older students. More positive relations with others was displayed by females, those pleased with their living conditions, those who went out and talked with friends more frequently and also by those suffering from poor physical health. Purpose in life was more evident among students involved in a romantic relationship and those with better mental health. Finally, students more likely to demonstrate self-acceptance were in a romantic relationship, were pleased with their living conditions, and enjoyed better mental health than others.

Students' personal characteristics that affected their character strengths' profile can be summarised as follows. Higher levels of wisdom and courage were more common amongst those who were involved in a romantic relationship, who were pleased with their living situation and who enjoyed better mental health; better physical health also contributed to showing courage. Human love was mostly exhibited by females and by those pleased with their living arrangements. More justice was displayed by older students, by those pleased with their living conditions and also by those enjoying better physical health. Temperance was more evident among students with better mental health. Finally, students more likely to demonstrate transcendence were older, had passed more exams, were pleased with their living conditions, saw or talked to their parents more frequently and enjoyed better mental health than others.

\subsection{Demographic and other sociological and psychological factors that impact subjective wellbeing and character strengths}

One of the foci of this study was to identify ways in which University students' outlook towards life was affected by a number of personal characteristics, demographic but also cognitive and behavioral in nature, such as wellbeing and character strengths. Overall, students were found to have a positive outlook in life, as suggested by their high scores in both subjective wellbeing and character strengths' scales; this finding supports Myers (2000) in his 
assertion that people generally tend to report high levels of life satisfaction. This finding of ours can be explained in relation to the particular life situations of our sample. Entering University usually signifies a major academic and life transition for emerging adults, given the high value assigned to academic achievement in the Greek society (Giovazolias, et al., 2008). Undoubtedly, this transition can be accompanied by a degree of stress or even adversity, since for the majority of youth it means that they leave their family for the first time to live on their own, assuming responsibility for their everyday needs and for any challenges that may present themselves (Leontopoulou, 2006). Nevertheless, once the initial, often stressful period of adaptation to University life is over, usually at the end of the first year of studies, students may view life at University not only as challenging, but also as an opportunity to grow. Indeed, older students in the present study demonstrated higher levels of a number of subjective wellbeing characteristics, such as autonomy, environmental mastery and personal growth, while they also appeared to possess higher levels of the character strengths of justice and transcendence. Being pleased with one's living conditions also contributed in a significant manner to youths' wellbeing, as revealed by its association with environmental mastery, positive relations with others and self-acceptance, and all character strengths apart from temperance. Good relationships and frequent contact with a romantic partner, friends and family seemed to heighten students' sense of environmental mastery, purpose in life, positive relations with others, self-acceptance, wisdom and courage.

\subsection{Subjective wellbeing, character strengths and physical and mental health}

Pulling on another strand, this study tried to determine the conditions under which emerging adults' self-evaluations of their physical and mental health affected their sense of subjective wellbeing and their character strengths. Good physical health was positively related to the wellbeing subscales of environmental mastery and self-acceptance, and also to the character strengths of courage and justice. Physical health was also a good predictor of the overall scales for both concepts, even if a less strong one than mental health. Indeed, good mental health appeared to be more pervasive, and a more reliable predictor of both wellbeing and character strengths, than physical health. In particular, it was associated with a wider array of positive characteristics of individuals, such as higher levels of the wellbeing aspects of environmental mastery, purpose in life, self-acceptance, and also of the character strengths of wisdom, courage, temperance and transcendence. One could speculate that, over the years, people who suffer from mental health problems may have discovered and got some practice in adaptive ways of handling them, either on their own, thus achieving more autonomy, or by eliciting the help of others, who may be close to them.

\subsection{Culture, subjective wellbeing and character strengths: Impact on positive psychology}

Yet another aim of this study was to examine some of the psychometric qualities of the character strengths measure in a different cultural setting than the more individualistic North American and North European context in which they have been developed and studied so far (Becker \& Marecek, 2008). In particular, this study sought to examine how the two constructs held within a more collective, Mediterranean cultural context, that of Greece. As was apparent from correlation analyses, the character strengths scale (VIA SCS) had high convergent validity, measured against the well-established subjective wellbeing (PWBS) measure. Regression analyses went some way toward indicating adequate construct validity for the VIA SCS scale, since the overall scale was predicted by personal growth and self-acceptance, while four of its 
own subscales predicted wellbeing. Taken together, these findings suggested that the two constructs are conceptually distinct, albeit related.

It appears, then, that two concepts that emerged from the positive psychology paradigm, namely subjective wellbeing and character strengths, are not only relevant in more individualistic societies, but also have validity in a more collective society, such as Greece. Still, the universality of positive psychology concepts and measures needs to be proven by further studies in different countries, and also by studies using diverse populations from each country.

\subsection{Limitations and future research}

Limitations of the present study included its cross-sectional nature, which could not allow for observations of development and change of student wellbeing and character strengths over time. In addition, the sample was somewhat biased towards a positive outlook. Further, assessment of student physical and mental health was based on just two self-report questions; nevertheless, some interesting findings emerged, which can be further explored in subsequent studies.

Further research is needed to tease out the conditions under which emerging adults maintain a positive outlook in life when faced with adversity. Subjective wellbeing and character strengths could conceivably play either a mediatory or even a moderating role under stress and adversity, be it personal or environmental in nature, with any number of variables as outcome, including attitudes toward help-seeking (for instance, academic performance, absence of psychopathology or positive adaptation, in general). Alternatively, subjective wellbeing and character strengths could be construed as outcome variables themselves in the face of stress, adversity or risk, in which case positive attitudes toward help-seeking could be conceptualized as mediators in the stress equation. Detailed research can attempt to solve the theoretical and empirical issues associated with the role of wellbeing and character strengths in the pathways that lead emerging adults to exhibit positive adaptation under challenging situations.

\section{Authors}

Sophie Leontopoulou

University of Ioannina

sleon@cc.uoi.gr

Sofia Triliva

University of Crete

\section{Publishing Timeline}

Received 15 March 2012

Accepted 1 April 2012

Published 29 August 2012

\section{References}

Becker, D., \& Marecek, J. (2008). Dreaming the American Dream: Individualism and positive psychology. Social and Personality Psychology Compass, 2(5), 1767-1780. http://dx.doi.org/10.1111/j.17519004.2008.00139.x

Brdar, I., \& Kashdan, T. B. (2010). Character strengths and well-being in Croatia: An empirical investigation of structure and correlates. Journal of Research in Personality, 44, 151-154. http://dx.doi.org/10.1016/j.jrp.2009.12.001 
Diener, E. (2000). Subjective well-being: The science of happiness and a proposal for a national index. American Psychologist, 55(1), 34-43. http://dx.doi.org/10.1037/0003-066X.55.1.34

Diener, E., Kesebir, P., \& Lucas, R. (2008). Benefits of accounts of well-being - for societies and for psychological science. Applied Psychology: An International Review, 57, 37-53. http://dx.doi.org/10.1111/j.1464-0597.2008.00353.x

Diener, E., Tamir, M., \& Scollon, C. N. (2006). Happiness, life satisfaction, and fulfillment: The social psychology of subjective well-being. In P. Van Lange (Ed.), Bridging Social Psychology, (pp. 319-324). Mahwah: Lawrence Erlbaum Associates.

Eysenck, H. (1991). Dimensions of personality: 16: 5 or 3? Criteria for a taxonomic paradigm. Personality and Individual Differences, 12, 773-790. http://dx.doi.org/10.1016/0191-8869(91)90144-Z

Giovazolias, T., Karademas, E., \& Kalantzi-Azizi, A. (2008) (Eds). Crossing internal and external borders. Practices for an Effective Psychological Counselling in the European Higher Education. Athens: Ellinika Grammata.

Halamandaris, K. F., \& Power, K. G. (1997). Individual differences, dysfunctional attitudes, and social support: A study of the psychosocial adjustment to university life of home students. Personality and Individual Differences, 22(1), 93-104. http://dx.doi.org/10.1016/S0191-8869(96)00175-4

Leontopoulou, S. (2006). Resilience of Greek youth at an educational transition point: The role of locus of control and coping strategies as resources. Social Indicators Research, 76, 95-126. http://dx.doi.org/10.1007/s11205-005-4858-3

Lopez, S. J., \& Edwards, L. M. (2008). The interface of Counseling Psychology and Positive Psychology: Assessing and promoting strengths. In S. D. Brown \& R. W. Lent (Eds.), Handbook of counseling psychology (4th ed., pp. 86-99). Hoboken, NJ: John Wiley \& Sons, Inc.

Luthans, F., Avey, J. B., Avolio, B. J., Norman, S. M., \& Combs, G. M. (2006). Positive psychological capital: Toward a micro-intervention. Journal of Organizational Behavior, 27, 387-393. http://dx.doi.org/10.1002/job.373

Markus, H., \& Kitayama, S. (1991). Culture and self: Implications for cognition, emotion and motivation. Psychological Review, 98, 224-253. http://dx.doi.org/10.1037/0033-295X.98.2.224

Miller, D. N., Nickerson, A. B., Chafouleas, S. M., \& Osborne, K. M. (2008). Authentically happy school psychologists: Applications of Positive Psychology for enhancing professional satisfaction and fulfillment. Psychology in the Schools, 45(8), 679-692. http://dx.doi.org/10.1002/pits.20334

Myers, D. G. (2000). The funds, friends, and faith of happy people. American Psychologist, 55(1), 56-67. http://dx.doi.org/10.1037/0003-066X.55.1.56

Niemiec, R. (2012). Mindful living: Character strengths interventions as pathways for the five mindfulness trainings. International Journal of Wellbeing, 2(1), 22-33. http://dx.doi.org/10.5502/ijw.v2i1.2

Noble, T., \& McGrath, H. (2008). The positive educational practices framework: A tool for facilitating the work of educational psychologists in promoting pupil wellbeing. Educational \& Child Psychology, 25(2), 119-134.

Park, N., Peterson, C., \& Seligman, M. E. P. (2004). Strengths of character and well-being. Journal of Social and Clinical Psychology, 23(5), 603-619. http://dx.doi.org/10.1521/jscp.23.5.603.50748

Park, N., Peterson, C., \& Seligman, M. E. P. (2006). Character strengths in fifty-four nations and the fifty US states. The Journal of Positive Psychology, 1(3), 118-129. http://dx.doi.org/10.1080/17439760600619567

Peterson, C., Park, N., \& Seligman, M. E. P. (2005). Assessment of character strengths. In G. P. Koocher, J. C. Norcross, \& S. S. Hill, III (Eds.), Psychologists' desk reference (2nd ed., pp. 93-98). New York: Oxford University Press.

Peterson, C., Park, N., \& Sweeney, P. J. (2008). Group well-being: Morale from a positive psychology perspective. Applied Psychology: An International Review, 57, 19-36. http://dx.doi.org/10.1111/j.14640597.2008.00352.x

Peterson, C., Ruch, W., Beermann, U., Park, N., \& Seligman, M. E. P. (2007). Strengths of character, orientations to happiness, and life satisfaction. The Journal of Positive Psychology, 2(3), 149-156. http://dx.doi.org/10.1080/17439760701228938 
Ryff, C. D. (1989). Happiness is everything, or is it? Explorations of the meaning of psychological wellbeing. Journal of Personality and Social Psychology, 57(6), 1069-1081. http://dx.doi.org/10.1037/0022$\underline{3514.57 .6 .1069}$

Saris, W. E. (2001). The Strength of the Causal Relationship between Living Conditions and Satisfaction. Sociological Methods \& Research, 30, 11-34. http://dx.doi.org/10.1177/0049124101030001002

Seligman, M. E. P. (2002). Authentic happiness: Using the new positive psychology to realize your potential for lasting fulfilment. New York: Free Press.

Seligman, M. E. P., \& Csikszentmihalyi, M. (2000). Positive psychology: An introduction. American Psychologist, 55(1), 5-14. http://dx.doi.org/10.1037/0003-066X.55.1.5

Stone, A. A., Schwartz, J. E., Broderick, J. E., Deaton, A. (2010). A snapshot of the age distribution of psychological well-being in the United States. Proceedings of the National Academy of Sciences, USA, 107, 9985-9990. http://dx.doi.org/10.1073/pnas.1003744107

Toner, E., Haslam, N., Robinson, J., \& Williams, P. (2012). Character strengths and wellbeing in adolescence: Structure and correlates of the Values in Action Inventory of Strengths for Children. Personality and Individual Differences, 52, 637-642. http://dx.doi.org/10.1016/j.paid.2011.12.014

Triandis, H. C. (1995). Individualism and collectivism. Boulder, CO: Westview press.

Veenhoven, R. (1996). Developments in satisfaction-research. Social Indicators Research, 37, 1-46. http://dx.doi.org/10.1007/BF00300268

Weiss, A., Bates, T.C., \& Luciano M. (2008). Happiness is a personal(ity) thing. Psychological Science, 19(3), 205-210. http://dx.doi.org/10.1111/j.1467-9280.2008.02068.x 